\title{
Herdsmen's Adaptation to Climate Changes and Subsequent Impacts in the Ecologically Fragile Zone, China
}

\author{
Yingcheng Liu,, Tao Zhang, ${ }^{2,3}$ Xiaoli Geng, ${ }^{1}$ Liansheng He, ${ }^{4}$ and Zhiguo Pang ${ }^{5,6}$ \\ ${ }^{1}$ Faculty of Resources and Environmental Science, Hubei University, Wuhan, Hubei 430062, China \\ ${ }^{2}$ Institute of Geographic Sciences and Natural Resources Research, Chinese Academy of Sciences, Beijing 100101, China \\ ${ }^{3}$ Center for Chinese Agricultural Policy, Chinese Academy of Sciences, Beijing 100101, China \\ ${ }^{4}$ State Key Laboratory of Environmental Criteria and Risk Assessment, Chinese Research Academy of Environmental Sciences (CRAES), \\ Beijing 100012, China \\ ${ }^{5}$ State Key Laboratory of Simulation and Regulation of Water Cycle in River Basin, Beijing 100048, China \\ ${ }^{6}$ China Institute of Water Resources and Hydropower Research, Beijing 100048, China
}

Correspondence should be addressed to Tao Zhang; zhangt.simlab@gmail.com

Received 18 July 2013; Revised 10 September 2013; Accepted 17 September 2013

Academic Editor: Xiangzheng Deng

Copyright (C) 2013 Yingcheng Liu et al. This is an open access article distributed under the Creative Commons Attribution License, which permits unrestricted use, distribution, and reproduction in any medium, provided the original work is properly cited.

\begin{abstract}
The change of land surface can exert significant influence on the future climate change. This study analyzed the effects of herdsmen's adaptation to climate changes on the livestock breeding, income, and land surface dynamics with a land surface parameterization scheme. The empirical analysis was first carried out on the impacts of the adaptation measures of herdsmen on their income in the context of the climate change with the positive mathematical programming (PMP) model on the basis of the household survey data in the Three-River Source Region, an ecologically fragile area in Qinghai Province, China. Then, the land surface parameterization process is analyzed based on the agent-based model $(\mathrm{ABM})$, which involves the herdsmen's adaptation measures on climate change, and it also provides reference for the land surface change projection. The result shows that the climate change adaptation measures will have a positive effect on the increasing of the amount of herdsman's livestock and income as well as future land surface dynamics. Some suggestions on the land use management were finally proposed, which can provide significant reference information for the land use planning.
\end{abstract}

\section{Introduction}

The climate change poses great threats to the human society and natural environment [1]. In order to adapt to the climate change, social agents would take some adaptation measures that have some synergistic effects on the dynamics of land surface. However, land surface dynamics would also react on the regional climate condition. Anthropogenic adaptation measures on climate change and variability may directly or indirectly influence the dynamic land surface change [2], which will have feedback effects on climatic conditions [3-6]. One of the effects of climate change on land surface dynamics reflects on the land surface dynamics response to climate change in the Alpine region. Some human decisions can somehow mitigate the climate change by influencing $\mathrm{CO}_{2}$ concentration according to previous studies that were conducted with the empirical or numerical methods $[3,4,6-$ 9], while some adaptation measures will indirectly change the climatic conditions through the intermediate impacts mainly derived from the change of land surface properties $[6,10-12]$. The Intergovernmental Panel on Climate Change (IPCC) Third Assessment Report has updated a framework of interrelationship between human adaptation' design and implementation and climate change $[13,14]$. However, previous studies have rarely analyzed the potential impacts of human's adaptation measures on land surface change which will result in destabilizing the climatic conditions in return [2].

There are still various difficulties in parameterizing the effects of human adaptation measures on the climate change 
for climate models' performance through the land surface dynamics. First, the current researches on the adaptation measures are mostly focused on the cost-benefit analysis, while there is less concern about effects of land surface change on climate which take adaptation measures into consideration $[15,16]$. Second, various views and preferences should be taken into consideration when implementing the systematic simulation for land surface during the implementation process of adaptation, which involves the policies, economy, social agents, and many stakeholders [17]. Third, the research object of adaptation measures is the ecosystem that is open, complex, and full of uncertainties, the knowledge about it is still limited, and therefore there are still some uncertainties in the implementation of adaptation measures [18]. To sum up, there are still a lot of difficulties in the land surface parameterization scheme in the climate models; for example, the parameters are complex, data are difficult to capture and quantify, and so forth, while those are the indispensable contents for the study of climate models.

The case study in typical ecofragile regions is helpful to comprehensively understand the importance of adaptation measures in land surface dynamics. In this study, the Three River Source Region in Qinghai Province, which has a fragile ecoenvironment and relatively simple industry structure, was selected as the study area. The future land surface was projected on the basis of the herdsmen's adaptation measures to climate change. An agent-based model (ABM) was developed, in which the adaptation measures would be considered in land surface projection for further climate models' performance in the ecologically fragile areas.

\section{Study Area}

2.1. Basic Information. The Three River Source Region, which is the headstream of Yangtze River, Yellow River, and Lancang River, is between $3139^{\prime}-3612^{\prime} \mathrm{N}$ and $8945^{\prime}-10223^{\prime} \mathrm{E}$ and in the southern part of Qinghai Province, China. It plays an important role as the ecological barrier for the ecological environment security and sustainable development of regions in the middle and lower reaches of Yangtze River and Yellow River in China as well as Southeast Asian countries. In the recent 30 years, the mean annual temperature is $3.96^{\circ} \mathrm{C}$, with an interannual increment of $0.04^{\circ} \mathrm{C}$, while the average annual precipitation is $500 \mathrm{~mm}$, with a small interannual growth rate of $0.17 \mathrm{~mm}$. The annual average precipitation gradually decreases from east to west on a whole. In addition, the frequency and intensity of climatic disasters also tended to increase in the past decades. The frequency of droughts showed a decreasing trend after 1961, but the duration time of droughts has extended, which exert great adverse impacts on husbandry production. The temperature has increased significantly since 1998, and the winter snowfall and frequency of snow disaster have also increased. Meanwhile, there is an obvious periodical change in the storm, that is, the storm frequency in Qinghai Province has increased notably since the 1990s, especially in the eastern husbandry area. The grasslands occupy the largest area in the study area, reaching $2.665 \times 10^{5} \mathrm{~km}^{2}$ and accounting for about $71.50 \%$ of the total land area of the study area. While the unused lands account for $16.50 \%$, the forest lands and waters account for $9.20 \%$ and $2.10 \%$, respectively. In the past 20 years, the cultivated lands and unused lands expanded by $46.2 \%$ and $0.64 \%$, respectively, while the forest lands and grasslands have decreased by $0.30 \%$ and $0.28 \%$, respectively. In 2009 , the population was $7.5 \times$ $10^{4}$, with the urbanization rate reaching $15.73 \%$. Among the 16 counties in the study area, more than half of them are key counties for poverty alleviation and development work, where the poor accounted for $63 \%$ of the total population. The animal husbandry is the main economic base for survival and development of pastoral minorities; the output value of which accounts for $57.28 \%$ of the total agricultural output.

2.2. Herdsmen's Adaptation to Climate Change. The adaptation of the farming and animal husbandry to climate change has been regarded as one of the key research spots, and adaptation measures are of great importance for mitigating the adverse effects of climate change [19]. The Three River Source Region is an important base for the development of animal husbandry in China, and it is very sensitive to climate change. The local social agents have various measures to adapt to the climate change, which were preliminarily classified mainly from the perspective of technology, engineering, management, and policy on the basis of achievements of previous researches on the adaptation measures on climate change [20]. The herdsmen's adaptation measures will have different effects, the spatiotemporal heterogeneity of which is mainly reflected by the resources endowment, population, climatic conditions, different social agents, cost-benefit, and other hidden effects that are not easy to be captured [17, 21, 22].

Herdsmen's decision on the adaptation measures can greatly affect the land surface dynamics [23]. There may be twofold impacts of these adaptation measures on the land use dynamics. Herdsmen's choice of the adaptation measures on climate change can affect their income, and the change of income will in turn affect the herdsmen's choices to adapt to the different cost, then it will further affect the decisionmaking behavior of the social agents. It has been discussed how economic benefits affect decision-making behavior of agents in previous works, with economic benefits represented with the cost of adaptation measures and its potential benefits in the ABM model $[24,25]$. We captured the economic benefits of climate change adaptation measures with the positive mathematical programming (PMP) model. In addition, this study also involved some adaptation measures that may have impact on land surface dynamics directly, for example, the effective artificial maintenance on grassland, which can prevent the degradation from grassland to desert or even wilderness.

The adaptation measures, which are the most typical and most concerned by the herdsmen, were selected from each category based on the household survey (Table 1). It shows that the major adaptation measures in the Three River Source Region mainly include the pest control, artificial maintenance of grassland, early warning mechanism of snow disasters, and fiscal subsidies, which represent the impacts of adaptation measures from the perspective of technology, engineering, extreme weather prevention and management, and fiscal subsidies, respectively. During the survey interview, the 
TABLE 1: Descriptions of various adaptation to climate change.

\begin{tabular}{|c|c|c|c|}
\hline Categories & Adaptation & Descriptions & Effects \\
\hline $\begin{array}{l}\text { Engineering } \\
\text { measure }\end{array}$ & $\begin{array}{l}\text { Artificial } \\
\text { maintenance } \\
\text { of grassland }\end{array}$ & $\begin{array}{l}\text { Combining captive breeding with } \\
\text { stocking. }\end{array}$ & $\begin{array}{l}\text { The captive breeding is conductive to the protection of } \\
\text { natural vegetation, while rescuing physical } \\
\text { consumption of livestock contributes to the growth of } \\
\text { livestock and directly increases the benefit. Meanwhile, } \\
\text { a large-scale captive breeding has the potential to } \\
\text { change the original pattern of land use [27]. }\end{array}$ \\
\hline $\begin{array}{l}\text { Technical } \\
\text { measure }\end{array}$ & Pest control & $\begin{array}{l}\text { Combining biological control and } \\
\text { chemical control. }\end{array}$ & $\begin{array}{l}\text { It is helpful to control the desertification and } \\
\text { degradation of grassland, protect grassland resources, } \\
\text { maintain the ecological balance of grassland, and } \\
\text { increase the income of herdsmen [28]. }\end{array}$ \\
\hline $\begin{array}{l}\text { Management } \\
\text { measure }\end{array}$ & $\begin{array}{l}\text { The early } \\
\text { warning } \\
\text { mechanism } \\
\text { of snow } \\
\text { disasters }\end{array}$ & $\begin{array}{l}\text { Early warning of monitoring of snow } \\
\text { disaster and layout of snow equipment. } \\
\text { Management and emergency plan of } \\
\text { snow disaster. }\end{array}$ & $\begin{array}{l}\text { Early warning work of disaster can help farmers } \\
\text { effectively and make them take measures in time to } \\
\text { reduce the loss of disasters. But the setting of } \\
\text { monitoring facilities and monitoring point will increase } \\
\text { the area of built-up land [29]. }\end{array}$ \\
\hline $\begin{array}{l}\text { Policy } \\
\text { measure }\end{array}$ & $\begin{array}{c}\text { Fiscal } \\
\text { subsidies }\end{array}$ & $\begin{array}{l}\text { Subsidy policy of livestock breeding, } \\
\text { subsidy of good seeds of artificial } \\
\text { planting forage seed, policy of production } \\
\text { subsidies, subsidy policy of animal } \\
\text { husbandry machinery purchase, and } \\
\text { subsidy policy of grazing prohibition for } \\
\text { nurture. }\end{array}$ & $\begin{array}{l}\text { Policy measures can avoid the herdsman's blind pursuit } \\
\text { of profit maximization which may destroy the } \\
\text { ecological balance. On the premise of guaranteeing the } \\
\text { herdsman's income, the government subsidy can help } \\
\text { the implication of policy and guide the farmer and } \\
\text { herdsman to maintain the reasonable pattern of land } \\
\text { use [30]. }\end{array}$ \\
\hline
\end{tabular}

herdsmen were asked about their preferences for adaptation measures on climate change, choice probabilities, and thinking ways, based on which the behavior rules were defined [26] and lay the foundation for the land surface parameterization scheme in the climate simulation. Additionally, the ABM model is used to simulate the effects of interaction between different social agents under particular conditions.

2.3. Data Collection and Processing. The household survey data used in this study were obtained from the questionnaire survey, which was implemented during August and October, 2012, in three counties of the Three River Source Region. First, three counties were selected from Tibetan Autonomous Prefecture of Golog, Tibetan Autonomous Prefecture of Huangnan, and Tibetan Autonomous Prefecture of Hainan. The selection of the sample counties was mainly based on three factors, that is, per capita grassland area, population density, and per capital GDP. Second, nine towns were selected in the three-sample counties with stratified random sampling. Then, two towns with the most and least grassland area were selected from the 9 towns, and thereafter two villages were selected in each sample town according to the employment situation in sectors except the animal husbandry. Finally, 10 herdsmen families were selected as the sample families from the herdsmen families with the large, medium, and small grassland area in each sample village. The questionnaire survey was carried out on 200 herdsman families, and the response rate of the questionnaires was $100 \%$, with 193 valid questionnaires and a ratio of valid questionnaire of $96.50 \%$. The contents of the questionnaire are as follows: population, land area (mainly including the grassland area), livestock production, sale of animal products, investment into the prevention and control of the damage from rats, subsidies granted for policy considerations, employment situation of sectors except animal husbandry, income from animal husbandry, and so forth.

In addition, the supplementary data consist of the basic geographic information data which are supported by Data Center for Resources and Environmental Sciences, Chinese Academy of Sciences (RESDC); the data mainly include land use data, DEM data, and topographic location data. The socioeconomic data are obtained from the Qinghai Statistical Yearbook, China Agriculture Yearbook, and China Animal Industry Yearbook. The natural environmental data and climate data are collected from the meteorological stations.

\section{Land Surface Parameterization Scheme}

3.1. Estimation Measures of the Impacts of Herdsmen's Adaptation. It is necessary to quantitatively analyze the economic benefits of the herdsmen's decision-making behavior about adaptation measures in order to better provide reference for the land surface parameterization scheme in the ABM model. There are many methods for quantitative assessment of adaptation measures, and this study used the PMP model proposed by Howitt in 1995 [31]. This model is somehow a popular approach to analyze the policy oriented environmental and economic problems, using even scarcely available information. The method has great flexibility and conforms to the basic hypothesis of economics of diminishing marginal returns, and these advantages support wide application of PMP model in policy effect analysis $[32,33]$.

There are mainly three steps to analyze the cost and benefit of the adaptation measures for climate change [25]. First, the constraint conditions were set in the linear programming model according to the observed values of the 
baseline period, and the dual prices (shadow prices) of the constraint conditions were further calculated with the linear programming model. Second, the slope of the average cost function in the objective function of the PMP model was calculated according to the dual price of the constraint conditions. Third, the corresponding parameters in the model were adjusted according to the need of the assessment of specific adaptation measures, and the parameters were obtained and then put in the objective function to obtain the optimal solution of the nonlinear programming for the investment into adaptation measures.

Finally, in order to analyze the impacts of the adaptation measures on the income of herdsmen, the PMP model was established on the basis of the household survey data of the herdsmen families as follows. The objective function is as follows:

$$
\mathrm{TMG}=\max \sum\left(p_{i} y_{i}+\operatorname{sub}-\left(\alpha_{i}+\frac{\gamma_{i}}{2 x_{i}}\right)\right) x_{i} .
$$

Constraint conditions are as follows:

$$
\begin{gathered}
\sum x_{i} \times l_{i} \leq L, \\
\sum x_{i} \leq \text { Area }, \\
\sum x_{i} \times q_{i} \leq I, \\
y_{i}=\beta_{0}+\beta_{1} \text { dtpro }+\beta_{2} \text { Gld }+\beta_{3} \text { POP }+\beta_{4} \mathrm{NPP} \\
+\beta_{5} \text { dtwater }+\beta_{6} \text { dtroad }+\beta_{7} \text { rain_cv } \\
+\beta_{8} \text { temp_cv }+\beta_{9} t_{0}+\beta_{10} t_{10}+\beta_{11} \text { conrodent } \\
+\beta_{12} \text { aprotect }+\beta_{13} \text { supint }+\mu,
\end{gathered}
$$

where TMG is the herdsmen's family income from livestock breeding; $y_{i}$ is the number of livestock per unit area of grassland; $x_{i}$ is the area of grasslands for the livestock; $p_{i}$ is the selling price of the livestock; $\alpha_{i}$ is the cost per unit area of grassland; $\gamma_{i}$ is the shadow price; $l_{i}$ is the labor input into each livestock; $q_{i}$ is the capital income per unit area of grassland; dtpro is the distance to capital of province; Gld is the area of grassland; POP is population; NPP is the net primary production; dtwater is the distance to water area; dtroad is the distance to road; rain_cv is the coefficient of variance of rain; temp_cv is the coefficient of variance of temperature; $t_{0}$ is the cumulative temperature above $0^{\circ} \mathrm{C} ; t_{10}$ is the cumulative temperature above $10^{\circ} \mathrm{C}$; conrodent is the rodent control; aprotect is the manual maintenance of grasslands; supint is the grazing intensity supervision; $\mu$ is the residual error.

In the PMP model mentioned previously, the objective function is defined as the maximization of the income of the herdsmen's family from livestock breeding for the following reasons. First, these adaptation measures implemented in the ecologically fragile areas aim to reduce the livestock loss of the herdsmen, and they consequently have positive significant impacts on the income of the herdsmen's family from livestock breeding. Second, there is a very low proportion of the income from crop production and other agricultural industries except animal husbandry in the total income of the herdsmen's family since the animal husbandry is the dominant industry in all the three counties where we do household survey in the Three River Source Region. Third, this study mainly focused on the impacts of these adaptation measures on the income of the herdsmen's family.

The income per unit area of grassland equals the product of capital income per unit area of grassland $q_{i}$, and the area of grasslands for grazing the livestock $x_{i}$, (2) expresses the constraint conditions of the labor; (3) expresses the constraint conditions of the grassland area; that is, the sum of the area of grasslands for grazing the livestock cannot exceed the total land area of the herdsmen's family; (4) is the constraint conditions of the capital; (5) provides the number of livestock per unit area of grassland under specific condition. Considering that in the system are mainly the herdsmen who graze the cattle and sheep and will not invest the income from other sources into animal husbandry, so the upper limit of total amount of investment into the livestock production should be set as the total income from livestock.

3.2. Parameterize the Adaptation in Land Surface Projection. According to different agents, the parameters of main decision-making behavior in the ABM model are different to simplify and simulate the adaptive behavior choice and the influence of each agent on climate change. Different agent has different preference for various adaptation measures, resulting in the different land surface dynamics effect. Therefore, this paper classified and extracted the agents in the study area and then determined their preference for adaptation measures according to the investigation and parameterized them.

Firstly, classify the counties and cities in Three River Source Region into three categories according to the analysis of their social and economic development, natural environment characteristics, and resource endowment characteristics; then the herdsmen's agents that are extracted from each category, mainly includes herdsmen's agent, half-herdsmen's agent, and restrictive herdsmen's agent. Secondly, design and determine the rules of agents' behavior through on-the-spot investigation about herdsmen's willingness to take climate change adaptation measures and other social economic and ecological environment consciousness, combined with the cost-benefit analysis of the adaptive measurements.

In addition, through the survey, it is found that in the Three River Source Region, the output of grasslands was relatively higher compared with that of other land use types. The grassland is also the main ecosystem in the study area, its ecosystem services function, such as livestock pasturing, water conservation, water purification, climate regulation, are indispensable to local individuals and communities. Therefore, the relative social agents are more willing to preserve and restore the grassland.

\section{Land Surface Dynamics Response to Adaptation for Climate Change}

4.1. Economic Analysis of Adaptation Measures. This study analyzed the economic benefits of adaptation measures for climate change with PMP model and explored the impacts 
of different adaptation measures on the livestock production and herdsmen's income based on the different context of climate change. The results show that the livestock production and the economic benefits have a spatial heterogeneity and scale effects (Figure 1).

Livestock number and animal industry income in the same county are correlated positively, which means that animal industry income would increase with the increase of livestock number. Adaptive technical measures make the livestock number and animal income of industry related positively under the high effect of temperature change rate condition. With the decrease of farm size, the income increment of livestock number and animal industry income would be declined gradually. Thus, we may deduce that the effect of the measure and the size of farm have a good positive correlation, and adaptive measure could increase herdsmen's income, but a more obvious impact on economic benefits of large-scale pastures. The implementation of nonengineering adaptation measures plays $0.8-1 \%$ of the effect on the animal husbandry income of the herdsman after estimating based on survey data. It is also found that the impact of nonengineering adaptation measures on income of animal husbandry is different due to the pasture size. Under the high effect of precipitation change condition, increment of livestock number would increase gradually with the decrease of grassland scale in the same county. However, the variation of animal industry income would decrease firstly and then increase with the decline of grassland scale, and the income increment of small-scale grassland is the biggest. Hence, engineering measure may develop the livestock production of the herdsman and the income of animal industry. The utility of engineering measure is related positively to grassland scale, but utility effect of water resource in small-scale grassland would be bigger, thus engineering measure has a bigger impact on livestock number and animal industry income in small-scale grassland. Abnormal climate may lead to the large-scale reduction on livestock number and animal industry income; however, herdsman's income may reduce onethird of loss under the condition of early warning mechanism. At the same time, the risk management is divided into 3 levels, and we evaluated whether they develop the management of early warning at the government level to adapt to climate change using PMP model. Simulation analysis shows that the establishment of early warning mechanism can avoid about $12 \%$ of economic loss in the large-scale grassland. The loss of small-scale grassland would be the minimum compared with the other two kinds of grassland when analyzed from the scale of grassland, that means that small-scale grassland has a good flexibility, and it can adjust the scale of production timely to minimize the losses. Government subsidy has a strong positive relationship with different scale of grassland and income of animal industry in the same county.

In conclusion, the four types of adaptation measures, which start from the character of climate impact factor in different typical ecologically fragile areas and can analyze filed sample data as well as getting the results, all can develop the livestock number and income of industry in different degrees from empirical analysis of PMP model. Therefore, positive adaptive measure has a positive effect on the herdsman to adapt to climate change.

4.2. Land Surface Dynamics. According to the simulation results based on ABM model, the land surface in the Three River Source Region shows some temporal and spatial characteristics during the next 50 years. Generally, the grassland area is increasing to a certain extent with an increment of $6.04 \%$, and the unused land gets moderate development and utilization, so the unused lands area experiences a reduction, with a rate of $14.64 \%$. Besides, the forest land area has some decrease and other lands use type almost maintain the same (Figure 2).

In the next 50 years, the area of changed land accounted for $6.65 \%$ of the total land area, which is dominated by the conversion from unused lands and forest lands to grasslands, accounting for $2.99 \%$ and $1.81 \%$ of the total land area, respectively. Specifically, as to the transformed lands, $74.92 \%$ of forestlands and $80.6 \%$ of unused lands are converted to grasslands, in contrast, the increasing of grassland area mainly comes from the forestland and unused land, with $34.39 \%$ and $56.67 \%$, respectively. The dramatic changes in grassland area are mainly because farms mainly pursue profit maximization and focus on considering the economic benefits of land use on the decision-making process. Grassland area would increase gradually and other land types would show a decreasing trend according to the simulation of the next 50 years. It means that the utilization way of land by farmers and herdsmen becomes simplex gradually, and dominant land use type is more and more obvious. Since single type of land will inevitably lead to the instability of ecological system, farmers and herdsmen should change the traditional way for adapting the nature, utilize adaptation measures rationally, not just pursue the revenue maximization of livestock yield and income of animal husbandry, but fully consider the rationality of land use pattern.

The distribution of land surface change simulated by $A B M$ is showed in Figure 3. The land use change mainly occurred in the central and east part of the study area; the east part was mainly dominated by the conversions from forest lands to grasslands and from grasslands to unused lands, while the central part was manifested by the development and utilization of unused land, thus showing the conversion from unused lands to grasslands. That is because of the restively low altitude and flat terrain in the eastern area which are relatively easy for reclaiming of unused land, and there is restively high precipitation which is advantageous to the pasture production and livestock farming. These favorable factors make the herdsman develop animal husbandry by reclaiming forest land and unused land to increase the income of animal husbandry.

\section{Conclusions and Discussions}

This study analyzed the economic benefits of the adaptation measures on climate change with the PMP model based on the survey data in the Three River Source Region, and then projected the land use change with the ABM model. This method may provide some reference for the research on the 


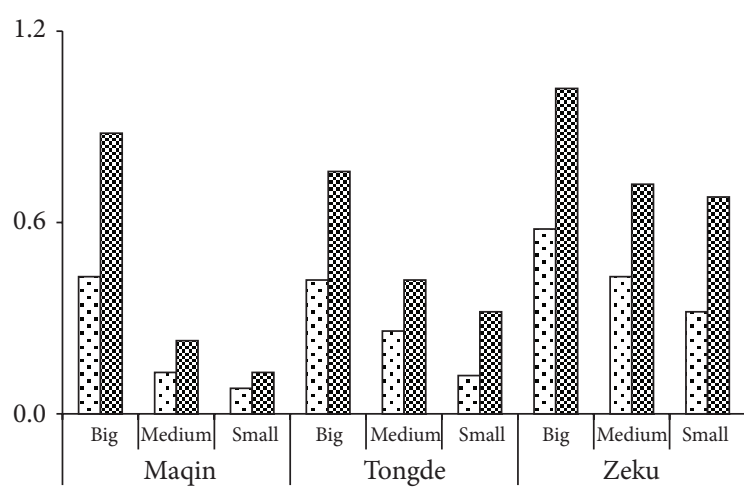

口 Proportion of livestock number change

a Proportion of husbandry income change

(a)

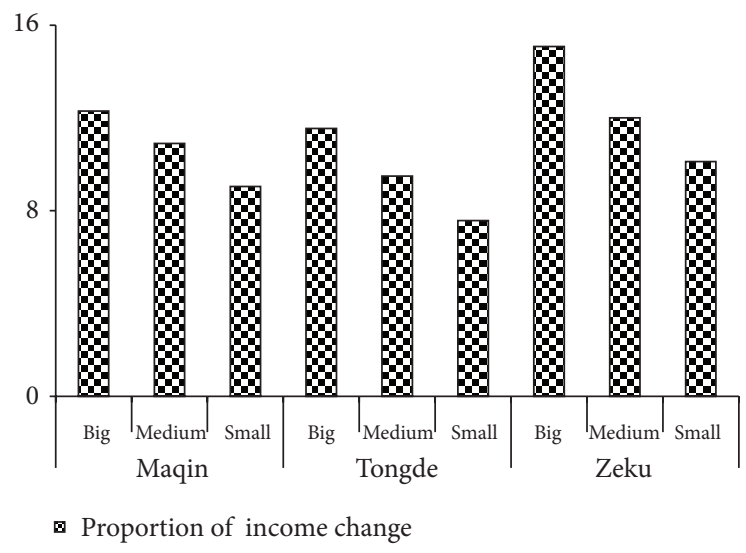

(c)

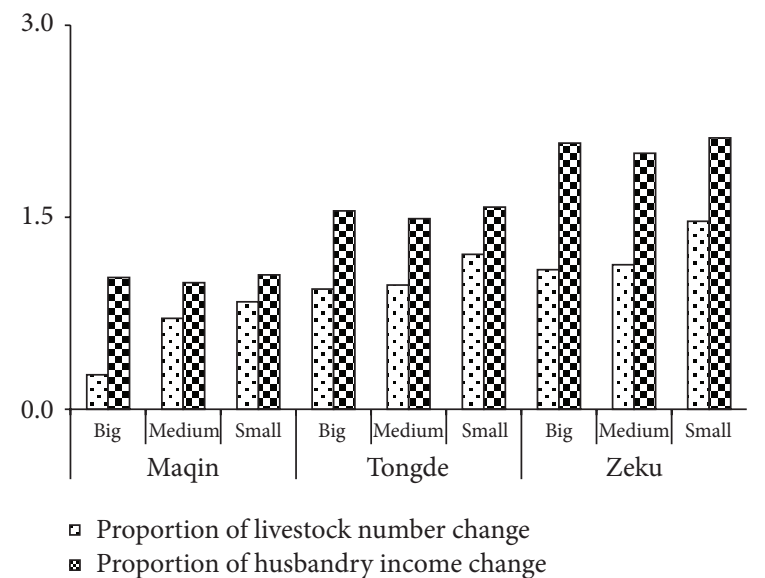

(b)

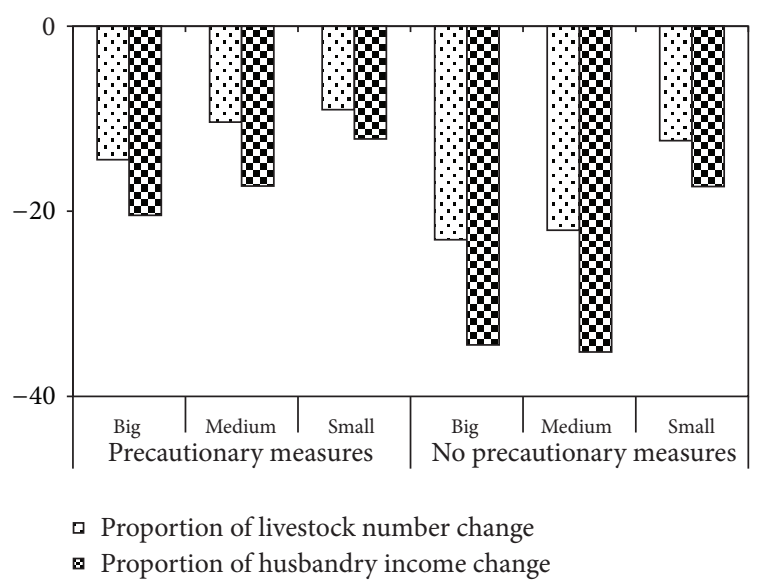

(d)

FIGURE 1: Mathematical analysis of herdsmen's adaptation to climate change including the technical measures (a), engineering measures (b), government subsidies (c), and extreme weather adaptation (d), from three-level pasture scales, such as large $\left(0.67 \mathrm{~km}^{2}-4.33 \mathrm{~km}{ }^{2}\right), \mathrm{medium}$ $\left(0.13 \mathrm{~km}^{2}-0.67 \mathrm{~km}^{2}\right)$, and small $\left(0.01 \mathrm{~km}^{2}-0.13 \mathrm{~km}^{2}\right)$.

climate simulation with different underlying land surface. The simulation result shows that the four kinds of adaptation measures will have different impacts on the development of the animal husbandry and economic benefits. Within a certain range, the larger the scale of grassland is, the more the income is. Therefore, the scale of pastures should be maintained at a certain appropriate range, and the government should continue to promote the return of the farmland to grassland and ecological migration projects. Besides, it is urgent to carry out more research on monitoring of ecological environment and ecosystem restoration, promote the comprehensive management of the ecological environment, and control the destruction of the ecological environment caused by herdsmen. According to the analysis with the ABM model on the basis of the herdsmen's adaptation measures to climate change, we could know that the adaptation measures will have synthetic impacts on the evolution of the underlying surface and promote the development and utilization of unused land and conversion to the forest lands and grasslands. The grassland increased by approximately $6.04 \%$, while the unused land decreased by $14.64 \%$. According to the simulation result of the land use in Three River Source Region during the next 50 years, we can find that all the land use types except grassland show a decreasing trend under the condition of adaptation measures. It means that the land utilization way of farmers and herdsmen gradually becomes simplex, and the predominance of grassland is more and more obvious. This suggests that herdsmen will ignore the rationality of land use when they excessively pursue the maximization of benefit.

The herdsmen are the main agent of economic activities and the basic unit of decision-making on the adaptation to climate change in the grazing districts, the decision-making behaviors of which have profound impacts on the land surface dynamics. The animal husbandry is the main economic source in the study area, and the adaptation measures on climate change will affect the economic income of herdsmen and of the land surface dynamics since the herdsmen's income will have effects on their decision-making on the adaptation measures and consequently lead to different land use change. This study analyzed the impacts of adaptation measures on 


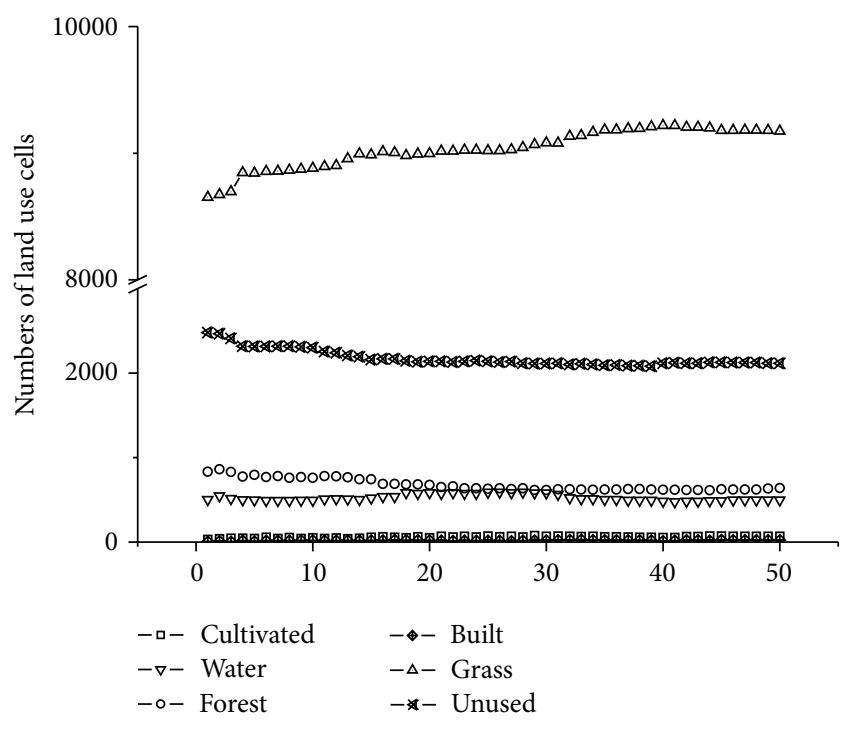

Figure 2: The underlying land surface structure in the next 50 years. The grid cell size is $2 \mathrm{~km} \times 2 \mathrm{~km}$.

climate change, but the land use classification is relatively rough, and the resolution is low, and there are many other factors influencing the land surface dynamics; therefore, it is necessary to implement some further researches in the future.

Although there are some uncertainties in the result, it can still provide value reference information for the land use management. Based on the result mentioned previously, some measures and suggestions of land use were put forward from all aspects. It is necessary to implement a number of measures in the overgrazing zones, for example, the reasonable land use planning, intensive development of land, control of excessive reclamation of grassland, and policy of returning grazing land to grassland, and grazing prohibition. Meanwhile, the government should provide food and economic compensation to the farmers and herdsmen so as to avoid the conversion from grassland to desert and other unfavorable land use types due to excessive degradation. Meanwhile, it is urgent to strengthen the prevention and control of pests, reduce the loss of grassland, and promote the utilization of existing grassland so as to further control the reclamation of grassland. Moreover, it is also urgent to establish the early warning mechanism of natural disasters in view of the increased frequency and intensity of natural disasters and their direct impacts on the herdsmen's economic benefit. The forest accounts for a relatively small proportion of the total area of the Three River Source Region; however, it provides abundant ecosystem services; therefore, it is necessary to make effort to manage and protect the forest in order to guarantee the sustainable development.

\section{Acknowledgments}

This research was supported by the National Key Program for Developing Basic Science in China (Grant no. 2012CB955700), the National Natural Science Funds for Distinguished Young Scholar (Grant no. 71225005), and

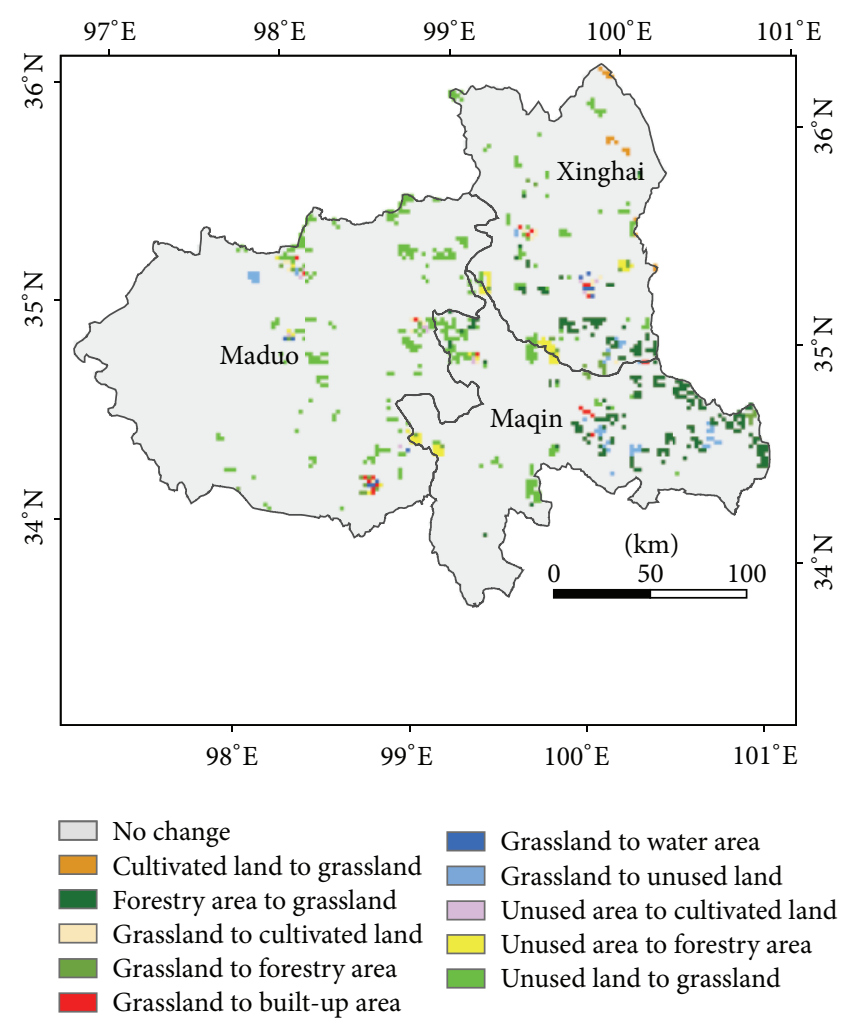

FIGURE 3: The spatial pattern of land surface change in the next 50 years. Only large proportion of land surface change is showed in this picture.

Exploratory Forefront Project for the Strategic Science Plan in IGSNRR,CAS (Grant no. 2012QY009).

\section{References}

[1] H. O. Pörtner and A. P. Farrell, "Ecology: physiology and climate change," Science, vol. 322, no. 5902, pp. 690-692, 2008.

[2] J. Smithers and B. Smit, "Human adaptation to climatic variability and change," Global Environmental Change, vol. 7, no. 2, pp. 129-146, 1997.

[3] M. Wang, X. Zhang, and X. Yan, "Modeling the climatic effects of urbanization in the Beijing-Tianjin-Hebei metropolitan area," Theoretical and Applied Climatology, vol. 113, no. 3-4, pp. 377-385, 2013.

[4] R. A. Pielke Sr., "Land use and climate change," Science, vol. 310, no. 5754, pp. 1625-1626, 2005.

[5] Y. Malhi, J. T. Roberts, R. A. Betts, T. J. Killeen, W. Li, and C. A. Nobre, "Climate change, deforestation, and the fate of the Amazon," Science, vol. 319, no. 5860, pp. 169-172, 2008.

[6] J. J. Feddema, K. W. Oleson, G. B. Bonan et al., "The importance of land-cover change in simulating future climates," Science, vol. 310, no. 5754, pp. 1674-1678, 2005.

[7] S. M. Sterling, A. Ducharne, and J. Polcher, "The impact of global land-cover change on the terrestrial water cycle," Nature Climate Change, vol. 3, no. 4, pp. 385-390, 2013.

[8] R. M. Bright, R. Astrup, and A. H. Strømman, "Empirical models of monthly and annual albedo in managed boreal forests of interior Norway," Climatic Change, pp. 1-14, 2013. 
[9] J. D. Wickham, T. G. Wade, and K. H. Riitters, "Empirical analysis of the influence of forest extent on annual and seasonal surface temperatures for the continental United States," Global Ecology and Biogeography, vol. 22, no. 5, pp. 620-629, 2012.

[10] J. Jin, S. Lu, S. Li, and N. L. Miller, "Impact of land use change on the local climate over the tibetan plateau," Advances in Meteorology, vol. 2010, Article ID 837480, 6 pages, 2010.

[11] G. B. Bonan, "Effects of land use on the climate of the United States," Climatic Change, vol. 37, no. 3, pp. 449-486, 1997.

[12] L. Bounoua, R. Defries, G. J. Collatz, P. Sellers, and H. Khan, "Effects of land cover conversion on surface climate," Climatic Change, vol. 52, no. 1-2, pp. 29-64, 2002.

[13] R. J. T. Klein, R. J. Nicholls, and N. Mimura, "Coastal adaptation to climate change: can the IPCC Technical Guidelines be applied?" Mitigation and Adaptation Strategies for Global Change, vol. 4, no. 3-4, pp. 239-252, 1999.

[14] B. Smit and O. Pilivosova, "The IPCC Third Assessment Report: Climate Change 2001, Working Group II: Impacts, adaptation and vulnerability," Adaptation to climate change in the context of sustainable development and equity, pp. 877-912, 2001, http:// www.ipcc.ch/ipccreports/tar/wg2/pdf/wg2TARchap18.pdf.

[15] R. S. J. Tol, S. Fankhauser, and J. B. Smith, "The scope for adaptation to climate change: what can we learn from the impact literature?" Global Environmental Change, vol. 8, no. 2, pp. 109123,1998 .

[16] K. de Bruin, R. B. Dellink, A. Ruijs et al., "Adapting to climate change in the Netherlands: an inventory of climate adaptation options and ranking of alternatives," Climatic Change, vol. 95, no. 1-2, pp. 23-45, 2009.

[17] B. Smit, I. Burton, R. J. T. Klein, and J. Wandel, "An anatomy of adaptation to climate change and variability," Climatic Change, vol. 45, no. 1, pp. 223-251, 2000.

[18] W. N. Adger, S. Dessai, M. Goulden et al., "Are there social limits to adaptation to climate change?" Climatic Change, vol. 93, no. 3-4, pp. 335-354, 2009.

[19] X. Z. Deng, C. H. Zhao, and H. M. Yan, "Systematic modeling of impact of land use and land cover changes on regional climate: a review," Advance in Meteorology, vol. 2013, Article ID 317678, 11 pages, 2013.

[20] B. Smit and M. W. Skinner, "Adaptation options in agriculture to climate change: a typology," Mitigation and Adaptation Strategies for Global Change, vol. 7, no. 1, pp. 85-114, 2002.

[21] J. D. Scheraga and A. E. Grambsch, "Risks, opportunities, and adaptation to climate change," Climate Research, vol. 10, no. 1, pp. 85-95, 1998.

[22] D. B. Lobell, M. B. Burke, C. Tebaldi, M. D. Mastrandrea, W. P. Falcon, and R. L. Naylor, "Prioritizing climate change adaptation needs for food security in 2030," Science, vol. 319, no. 5863, pp. 607-610, 2008.

[23] W. N. Adger, S. Huq, K. Brown, D. Conway, and M. Hulme, "Adaptation to climate change in the developing world," Progress in Development Studies, vol. 3, no. 3, pp. 179-195, 2003.

[24] J. G. Polhill, L. A. Sutherland, and N. M. Gotts, "Using qualitative evidence to enhance an agent-based modelling system for studying land use change," Journal of Artificial Societies and Social Simulation, vol. 13, no. 2, 10 pages, 2010.

[25] L. R. Izquierdo, N. M. Gotts, and J. G. Polhill, "Case-based reasoning, social dilemmas, and a new equilibrium concept," Journal of Artificial Societies and Social Simulation, vol. 7, no. 3, 2004 .
[26] P. M. Kelly and W. N. Adger, "Theory and practice in assessing vulnerability to climate change and facilitating adaptation," Climatic Change, vol. 47, no. 4, pp. 325-352, 2000.

[27] S. C. Dong, C. J. Chang, and H. Y. Wang, "Ecological crisis and countermeasures of the Three Rivers' headstream region," Journal of Natural Resources, vol. 17, no. 6, pp. 713-720, 2002.

[28] C. A. Gillies and R. J. Pierce, "Secondary poisoning of mammalian predators during possum and rodent control operations at Trounson Kauri Park, Northland, New Zealand," New Zealand Journal of Ecology, vol. 23, no. 2, pp. 183-192, 1999.

[29] H. H. Einstein and R. Sousa, "Warning systems for natural threats," Assessment and Management of Risk For Engineered Systems and Geohazards, vol. 1, no. 1, pp. 3-20, 2007.

[30] S. H. Eriksen and K. O'Brien, "Vulnerability, poverty and the need for sustainable adaptation measures," Climate Policy, vol. 7, no. 4, pp. 337-352, 2007.

[31] R. Howitt, "Positive mathematical programming," American Journal of Agricultural Economics, vol. 77, no. 2, pp. 329-342, 1995.

[32] R. E. Howitt, "PMP based production models-development and integration," in Proceedings of the European Association of Agricultural Economists International Congress, Copenhagen, Denmark, 2005.

[33] T. Heckelei, W. Britz, and Y. Zhang, "Positive mathematical programming approaches-recent developments in literature and applied modelling," Bio-Based and Applied Economics, vol. 1, no. 1, pp. 109-124, 2012. 

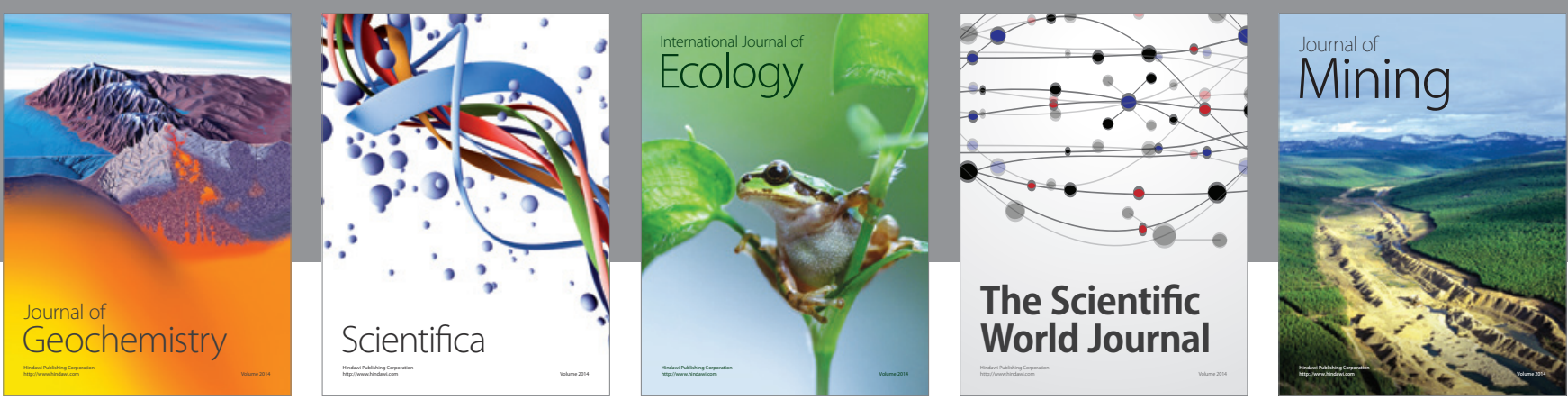

The Scientific World Journal
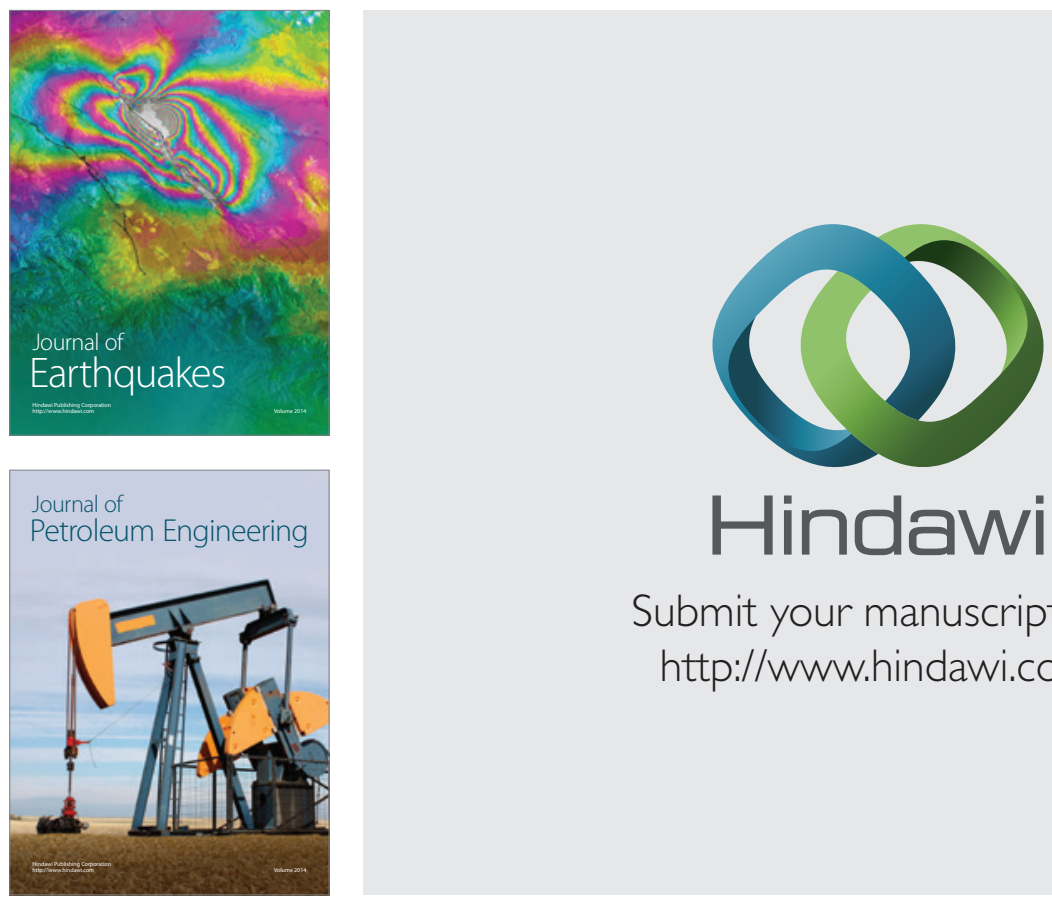

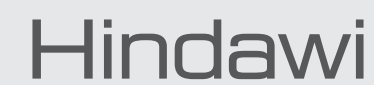

Submit your manuscripts at

http://www.hindawi.com
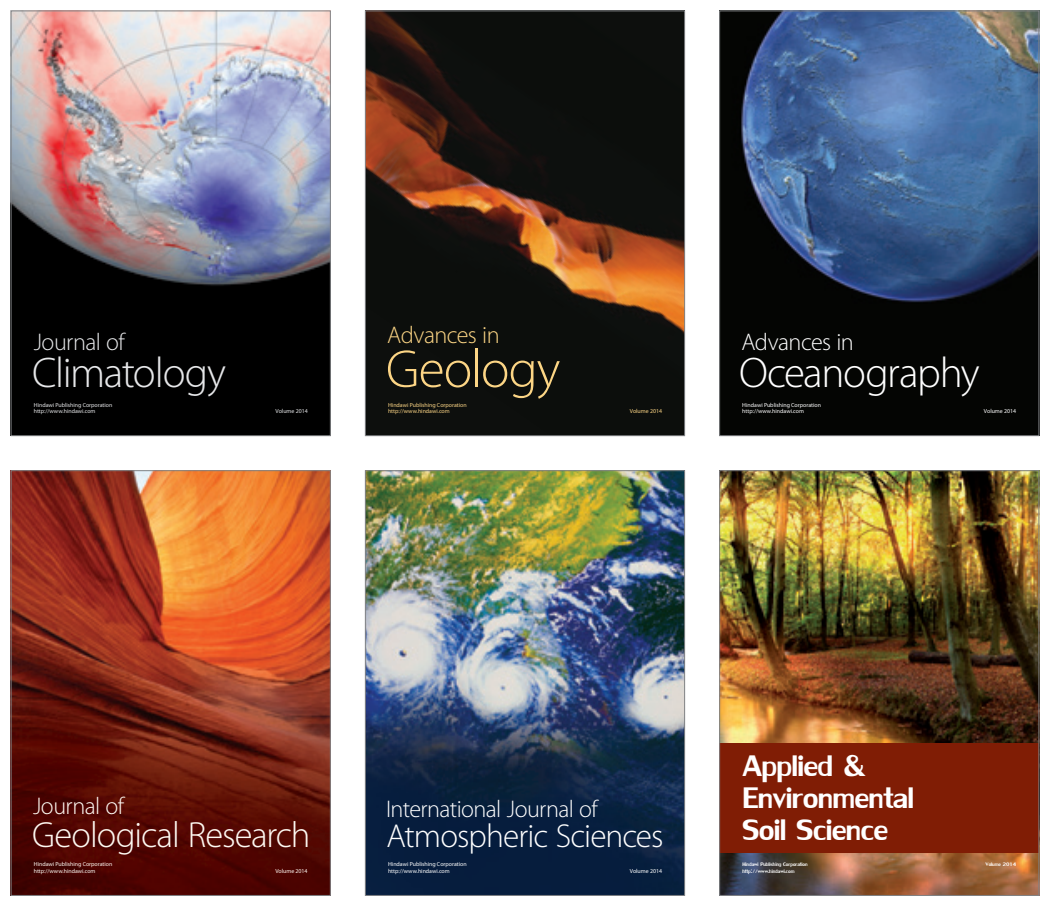
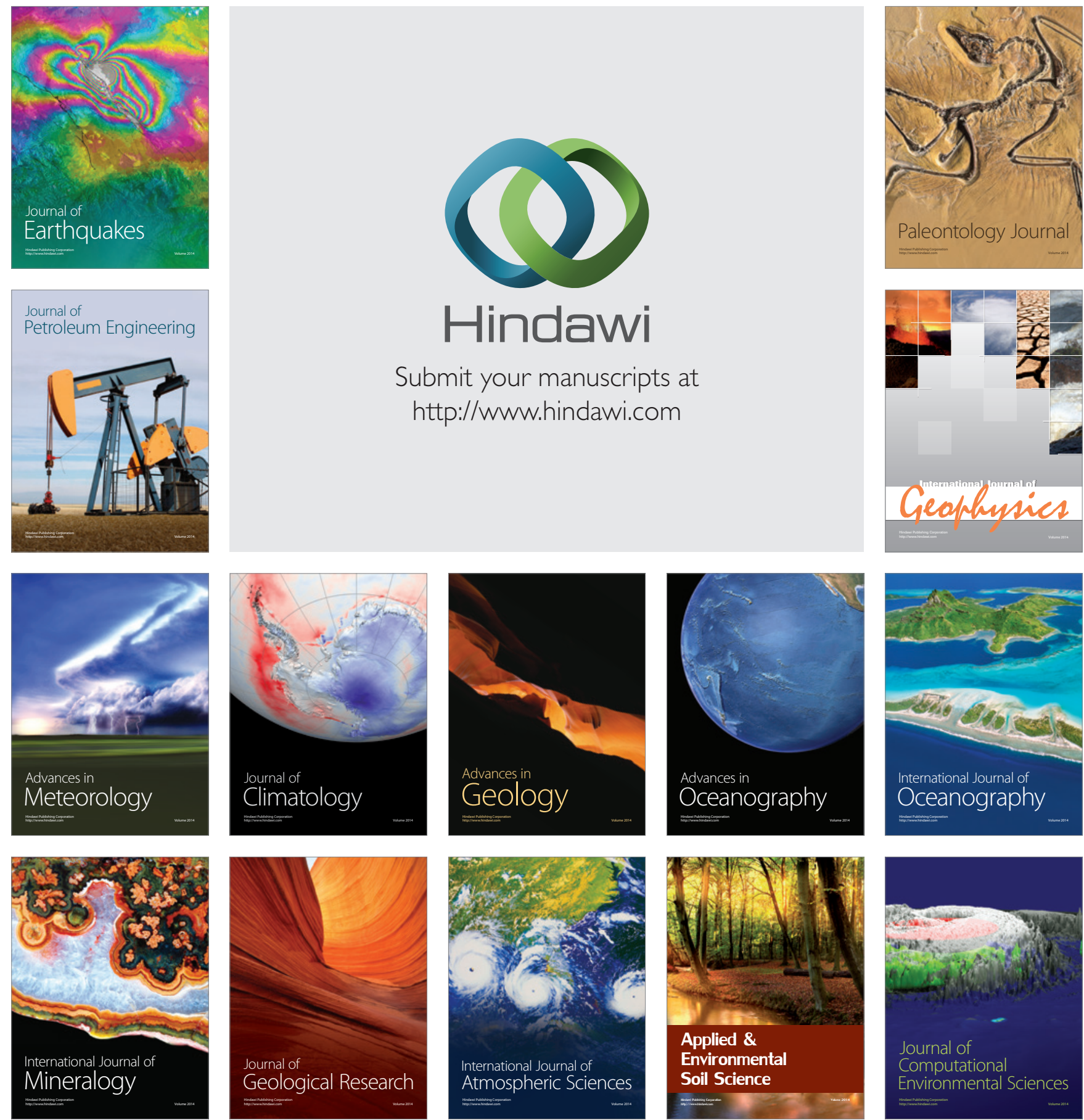